\title{
Association of global sagittal spinal deformity with functional disability two years after total hip arthroplasty
}

Yoshinori Okamoto ${ }^{*}$, Hitoshi Wakama, Tomohiro Okayoshi, Shuhei Otsuki and Masashi Neo

\begin{abstract}
Background: The relationship between spinopelvic alignment and functional disability after total hip arthroplasty (THA) has not been fully elucidated despite the growing recognition of its importance on patient-reported outcome measures. Therefore, our aim was to assess the effect of global sagittal spinal deformity on post-operative disability.

Methods: This analysis was based on 208 cases of THA, with functional disability measured at a follow-up of 2 years. The Hip Disability and Osteoarthritis Outcome Score-Joint Replacement (HOOS-JR), ranging from a scale of 0 (complete joint disability) to 100 (perfect joint health), was used to divide eligible patients into two groups, namely with and without disability, using a score of 70 as the cut-off. The following factors were compared between the two groups using multivariate analysis: age, sex, body height, body mass index, spinopelvic parameters, and surgeon experience. To identify the cut-off value of the parameters for predicting disability (HOOS-JR $<70 / 100)$, we used the receiver-operating characteristic curve.
\end{abstract}

Results: The disability (30 hips) and control (178 hips) groups showed a significant difference in pre-operative body height ( $p=0.020)$, T1 pelvic angle divided by pelvic incidence (T1PA/PI; $p=0.018)$, PI minus lumbar lordosis $(p=0.027)$, post-operative HOOS-JR $(p=0.010)$, patient satisfaction $(p=0.033)$, and the modified Harris Hip Score $(p=0.038)$. On multivariate analysis, the following factors were associated with persistent disability: T1PA/PI > 0.2 (odds ratio [OR], 2.11; 95\% confidence interval [CI], 1.19-4.14; $p<0.001$ ) and height $<148 \mathrm{~cm}$ equivalent to legal standards as short stature $(\mathrm{OR}, 1.26 ; 95 \% \mathrm{Cl}, 1.09-1.48 ; p=0.011)$. The cut-off value of pre-operative T1PA/PI was $>0.19$, with a sensitivity of $95 \%$ and specificity of $85 \%$. Post-operative satisfaction $(p<0.001)$, HOOS-JR $(p=0.023)$, and EuroQol 5-Dimension $(p=0.041)$ differed between the two groups when the pre-operative cut-off value was chosen as 0.2 .

Conclusions: A T1PA/PI > 0.2 was associated with greater disability after THA. Clinicians should be aware that patientrelated factors, including global spinal deformities, particularly in patients with a short stature, can influence THA outcomes at 2 years postoperatively.

Keywords: Disability, Global sagittal deformity, Spinopelvic alignment, T1 pelvic angle, Total hip arthroplasty

\footnotetext{
*Correspondence: ort141@osaka-med.ac.jp

Department of Orthopedic Surgery, Osaka Medical and Pharmaceutical University (Osaka Medical College), 2-7 Daigaku-machi, Takatsuki, Osaka 5698686, Japan
}

(c) The Author(s). 2021 Open Access This article is licensed under a Creative Commons Attribution 4.0 International License, which permits use, sharing, adaptation, distribution and reproduction in any medium or format, as long as you give appropriate credit to the original author(s) and the source, provide a link to the Creative Commons licence, and indicate if changes were made. The images or other third party material in this article are included in the article's Creative Commons licence, unless indicated otherwise in a credit line to the material. If material is not included in the article's Creative Commons licence and your intended use is not permitted by statutory regulation or exceeds the permitted use, you will need to obtain permission directly from the copyright holder. To view a copy of this licence, visit http://creativecommons.org/licenses/by/4.0/. The Creative Commons Public Domain Dedication waiver (http://creativecommons.org/publicdomain/zero/1.0/) applies to the data made available in this article, unless otherwise stated in a credit line to the data. 


\section{Background}

Despite the proven efficacy of total hip arthroplasty (THA), one in 7-14 patients still report persistent dissatisfaction on short- to medium-term follow-up [1-3]. Some studies have identified factors which influence patient satisfaction or functional disability after THA, such as pre-operative patient expectations, the degree of improvement achieved, mental health status, comorbidities, and pain relief $[1,2,4]$. Although patient satisfaction plays an important role in assessing therapeutic effects, the impact of the pre-operative spinopelvic alignment on disability after THA has not been reported, even if only over a short term.

Pertinent issues have been raised about the increased incidence of concurrent hip osteoarthritis (OA) and spinal deformities in aging populations [4], with spinal deformities identified in approximately $20-44 \%$ of patients undergoing THA [5, 6]. A greater understanding of the association between sagittal spinopelvic alignment and outcomes is also thought to minimise instances of cumbersome THA dislocation or revision [7, 8]. However, little is known about how sagittal spinal alignment affects THA outcomes, especially patient functional disability after THA [4, 9-11]. The key to successful THA necessitates a further comprehensive analysis of the influence of sagittal spinopelvic interactions on functional outcomes. This argument is important to evaluate considering the importance of patient-reported outcome measures (PROMs) in today's healthcare system.

Furthermore, most large databases, such as the national joint registry or multi-centre studies, are limited to the analysis of PROMs, implant longevity, or complications [12-17]. However, no study has investigated the relationship between spinopelvic alignment and patient disability after THA. A better understanding of patient-related factors is essential to improve the prognosis of THA. Of these factors, resolving the controversy regarding the concurrence of sagittal spinal imbalance and hip OA for clinicians, patients, and policymakers would be particularly important, considering the general super-ageing of our society. Accordingly, the purpose of our study was to determine whether global sagittal spinal deformity is associated with functional disability after THA.

\section{Methods}

\section{Participants}

The study was approved by the institutional review board of our hospital (approval number 1912) and performed in line with the principles of the Declaration of Helsinki (1964) and its subsequent amendments. All patients provided written informed consent for their participation in the study and the publication of their data. Between January 2015 and December 2018, 285 primary THAs were performed at our institution. Of these, 246 patients (270 hips), who were Asian, completed a minimum follow-up of 2 years and were enrolled into this study. From this group, we excluded 34 patients (58 hips) who had undergone a staged bilateral THA history (46 hips) or had a history of spinal surgery (five hips), new vertebral compression fracture (three hips) [18], THA with subsequent lumbar spine fusion (two hips), or simultaneous THA (two hips) during the follow-up period. For a few patients, the femoral head was not visible on radiographs and, thus, the pelvic incidence (PI) could not be evaluated (four hips) [19]. Ultimately, 208 patients (208 hips) were included in our study (Fig. 1). Of these, secondary hip OA was the most common (165 hips, 79.3\%), followed by primary OA and osteonecrosis of the femoral head (18 hips for each, 8.7\%) [20].

\section{Surgical procedure and post-operative protocol}

All THAs were performed by six experienced arthroplasty surgeons using a direct lateral approach with the patient in the lateral decubitus position [21, 22]. Of these, 130 required acetabular structural bone grafting for the dysplastic acetabulum [22]. The highly cross-linked polyethylene flanged socket (K-MAX CLHO flanged cup, Kyocera Medical, Osaka, Japan) and a cobalt-chromium head with a polished stem (SC stem, Kyocera Medical, Osaka, Japan) were fixed using bone cement (CMW Endurance, DePuy, Blackpool, UK). All patients were allowed full weightbearing post-operatively, with the use of crutches encouraged, as needed, for the first 3 months. This was according to a standardised fast-track post-THA protocol, which included standardised physical therapy with mobilisation after drain removal.

\section{Clinical evaluations}

Before and at 2 years after THA, we used the modified Harris Hip Score (HHS) and the Trendelenburg sign as measures of hip function [23, 24]. The incidence of complications was investigated. Data were analysed in a blinded fashion.

\section{Patient-reported outcome measures}

We evaluated the patient-reported outcomes preoperatively and at 2 years post-operatively. The Hip disability and Osteoarthritis Outcome Score, Joint Replacement (HOOS-JR) is a short PROM developed to efficiently evaluate end-stage hip OA in patients undergoing THA. The HOOS-JR is a six-question survey derived from the original 40-question HOOS. Each item on the HOOS-JR is scored from 0 to 28 and then converted into an interval score from 0 (total joint related disability) to 100 (perfect joint health) $[24,25]$. A $100-\mathrm{mm}$ visual analogue scale (VAS) was used to evaluate hip pain and patient satisfaction. The $100-\mathrm{mm}$ VAS-pain and satisfaction score was categorised for analysis from a range of " 0 " $\mathrm{mm}$ (no pain and very satisfied) to 


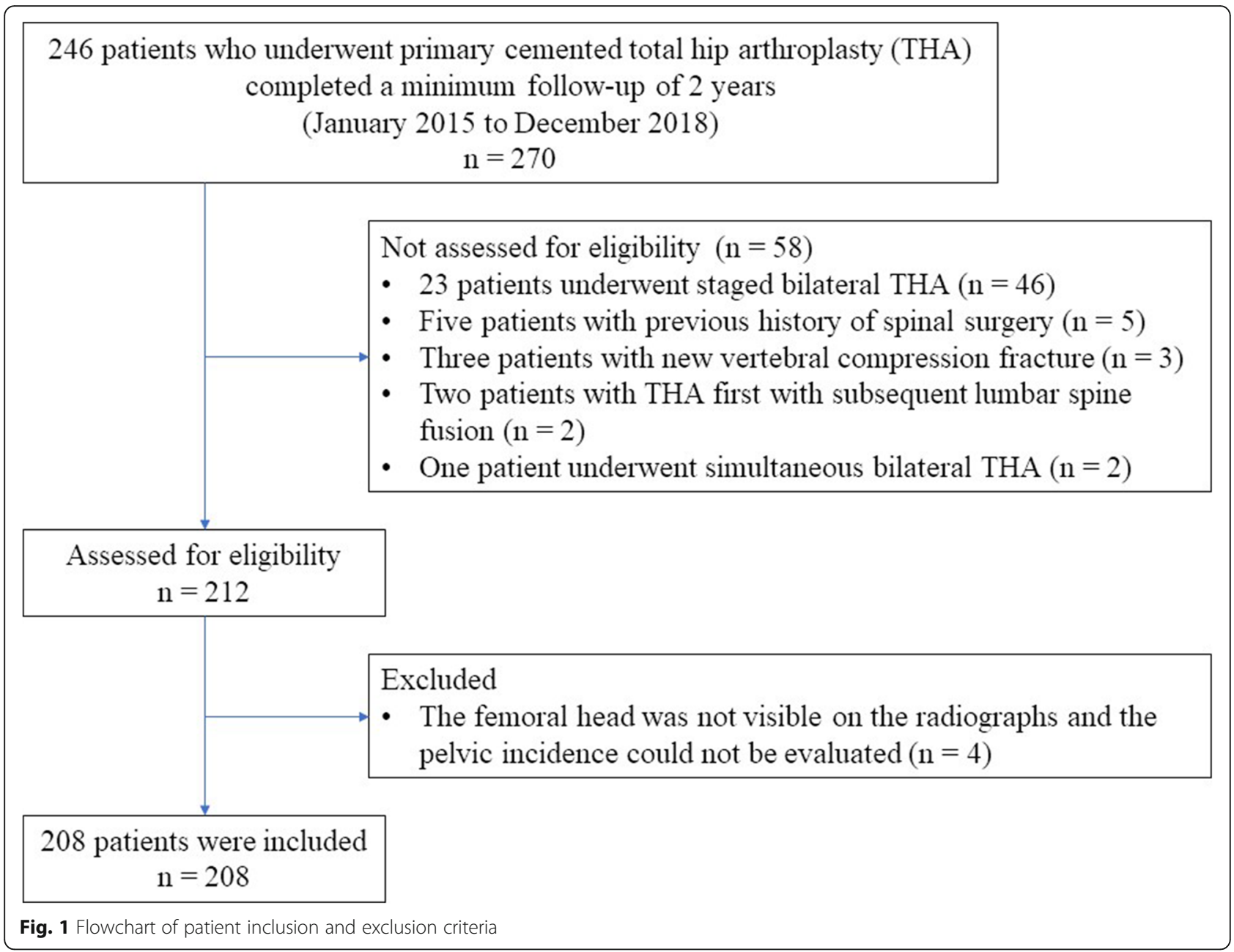

"100" mm (worst pain imaginable and completely dissatisfied) $[15,24]$. The EuroQol 5-Dimension 5-Level (EQ-5D) scale was used as a measure of patient-reported quality of life $[24,26]$.

\section{Radiological evaluations}

Spinopelvic alignment was assessed before and at 2 years after THA, with the patients in the standing position [27]. Radiographs obtained within 1 month pre-operatively were reviewed for vertebral fractures by an independent arthroplasty surgeon with 10 years of experience. Vertebral fractures were identified using a semiquantitative method, namely a decrease in the height of the vertebral body $>20 \%$ [18]. Radiological measures of the sagittal spinopelvic alignment were obtained using a protractor with $1^{\circ}$ increments as follows: C7 sagittal vertical axis (SVA), lumbar lordosis (LL), PI, pelvic tilt (PT), and T1 pelvic angle (T1PA) $[4,6$, 19, 23, 28] (Fig. 2). The T1PA, a measure of the global malalignment and/or compensation through pelvic retroversion, was defined as the angle between the line from the femoral head axis to the centre of the T1 vertebral body and the line from the femoral head to the centre of the S1 superior end plate. A T1PA divided by PI (T1PA/PI) $>0.2$, which provides an angular measure of global sagittal spinal deformity, was associated with lower health-related quality of life in patients undergoing treatment for adult spinal deformity [6]. Osseous complications at the reattached fragment were evaluated on anterior-posterior radiographs obtained 2 years after THA [21, 22].

To calculate the reliability of the spinopelvic alignment, three experienced arthroplasty surgeons independently evaluated the radiographic parameters, with each observer completing three randomly selected measurements at a mean interval of 4.1 (range, 3.6 to 4.4 ) weeks for 15 patients each. All observers were orthopaedic surgery specialists, with $>6$ years of experience. Additionally, they had at least completed a 1-year fellowship in hip surgery under a mentor. Intra- and inter-rater reliability was calculated with a tolerance error of $<2^{\circ}[29]$.

\section{Statistical analysis}

Statistical analyses were performed using JMP 14 software (SAS Institute Inc., Cary, NC, USA), with $p$-values $<0.05$ considered statistically significant. We defined a 


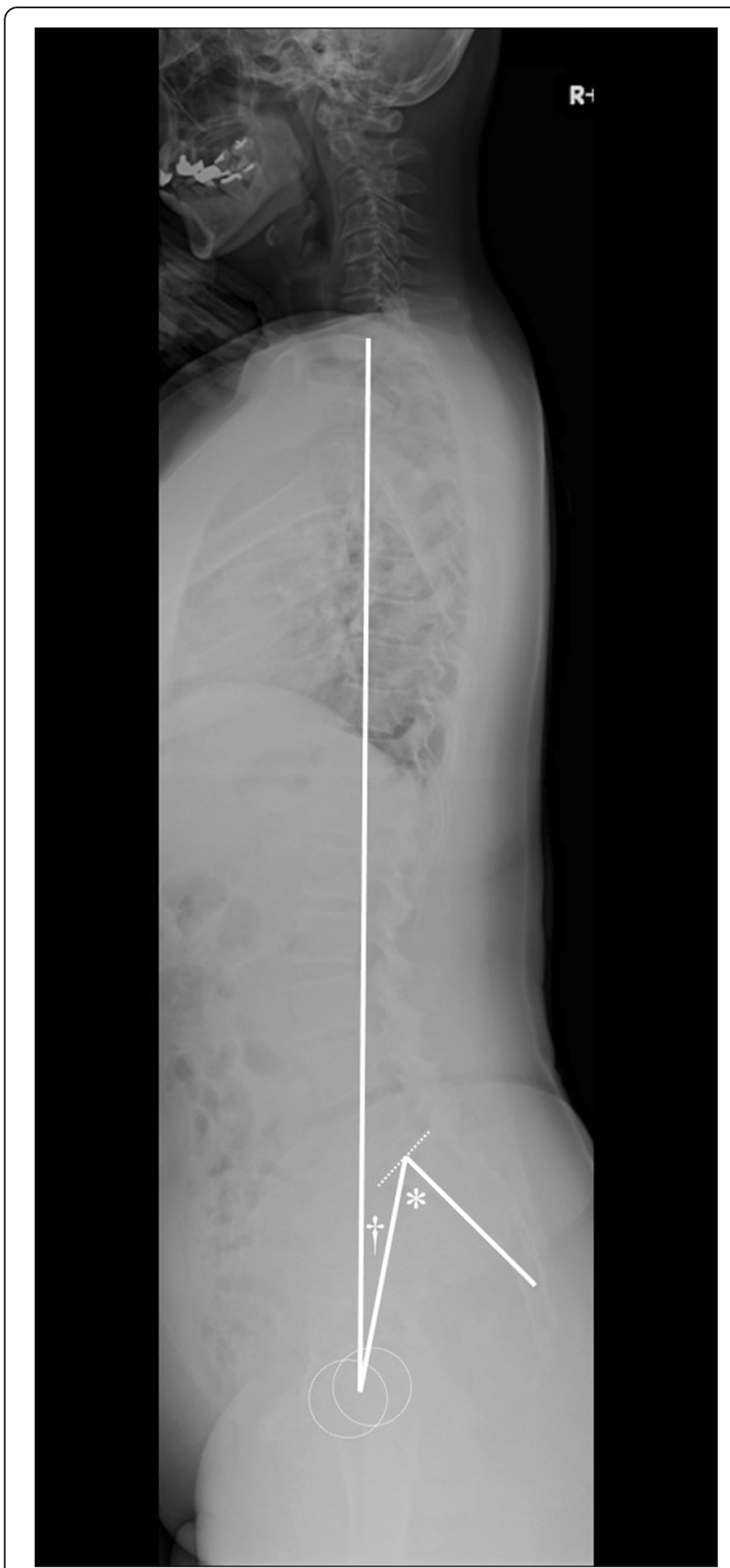

Fig. 2 A radiograph was used to evaluate the pelvic incidence $(*)$ and $\mathrm{T} 1$ pelvic angle (T1PA, + ) of a patient with a global sagittal spinal deformity $[6,19]$. T1PA is defined as the acute angle by the intersection of a line from the centre of the $\mathrm{T} 1$ vertebral body to the femoral heads and a line from the femoral heads to the centre of the superior sacral end plate. This interplay suggests useful information from both the sagittal vertical axis and pelvic tilt simultaneously to measure the geometry of global spinal deformity

HOOS-JR of 70 as a clinically significant cut-off value and divided patients into the following two groups for comparison: the disability group, who had a postoperative HOOS-JR < 70, indicating hip disability, and the control group, who had a HOOS-JR $\geq 70$, indicating no disability [30].

Differences in the measured variables between the two groups were evaluated using the Mann-Whitney U test for continuous variables. Categorical variables were compared using Fisher's exact or chi-squared tests as per the data distribution. The Steel-Dwass test was used to reveal the relationship between the grade of $\mathrm{OA}$ according to the Kellgren-Lawrence classification and spinopelvic parameters. To identify independent risk factors for the residual disability group, logistic regression analyses were performed. Factors, such as age, sex, body height, body mass index, spinopelvic parameters, and surgeon experience, were analysed using an exploratory univariate analysis followed by a multivariate analysis $[1,4,7$, $13,15-17,22]$. Short stature was typically defined as a height $<147.23 \mathrm{~cm}$ by legal standards [13]. Surgeons were classified into the following groups: orthopaedic specialists $<8$ years', $8-15$ years', and $\geq 15$ years' experience after certification [15].

A multicollinearity test was performed with the variance inflation factor set at $<10$. Age was included as a confounding factor. To identify the cut-off value of the parameters for predicting disability, we used the receiver-operating characteristic (ROC) curve.

\section{Results}

The disability (30 hips, 14.4\%) and control (178 hips, 85.6\%) groups showed a significant difference in body height $(p=0.020)$, pre-operative T1PA/PI $(p=0.018)$, PI minus LL $(p=0.027)$, post-operative Trendelenburg sign $(p<0.001)$, osseous complications $(p=0.006)$, HOOS-JR $(p=0.010)$, satisfaction $(p=0.033)$, and modified HHS $(p=0.038)$. With respect to LL and T1PA, the differences between the two groups were significant both preoperatively ( $p=0.016$ and $p=0.041$, respectively) and postoperatively ( $p=0.018$ and $p=0.041$, respectively) (Table 1). However, no significant differences were found between the two groups in terms of complications. Deep infections (one hip, 0.6\%), peri-prosthetic femoral fractures (two hips, 1.1\%), and post-operative dislocation (one hip, $0.6 \%$ ) were observed in the control group, whereas dislocation, fracture, infections, and permanent sciatic nerve palsy (one hip for each, 3.3\%) occurred in the disability group. In patients classified as Kellgren-Lawrence grade III, no differences between the groups were seen with respect to PI or PT postoperatively; however, PT in grade IV differed significantly $(p=0.034)$ (Fig. 3).

On regression analysis, patient age at the time of surgery was associated with neither pre-operative nor postoperative measures. The independent variables associated with greater disability were a T1PA/PI $>0.2$ (versus a T1PA/PI $\leq 0.2$; odds ratio, 2.11; $p<0.001$ ) and body 
Table 1 Baseline characteristics and comparison of the disability and control groups

\begin{tabular}{|c|c|c|c|}
\hline & $\begin{array}{l}\text { Disability group } \\
n=30\end{array}$ & $\begin{array}{l}\text { Control group } \\
n=178\end{array}$ & $P$ value \\
\hline Age (years) & $74.9 \pm 7.1$ & $74.2 \pm 7.3$ & 0.745 \\
\hline Male (n, \%) & $4,13.3$ & $21,11.8$ & 0.811 \\
\hline Body height (cm) & $153.1 \pm 3.1$ & $156.7 \pm 4.3$ & $0.020^{*}$ \\
\hline Body height < $148 \mathrm{~cm}(\mathrm{n}, \%)$ & $6,20.0$ & $12,6.7$ & $0.042^{*}$ \\
\hline Body mass index $\left(\mathrm{kg} / \mathrm{m}^{2}\right)$ & $25.3 \pm 3.1$ & $24.5 \pm 3.1$ & 0.723 \\
\hline Pre-operative diagnosis (n, \%) & & & 0.174 \\
\hline Primary osteoarthritis ${ }^{\mathrm{a}}$ & $3,10.0$ & $15,8.4$ & \\
\hline Secondary osteoarthritis ${ }^{\mathrm{a}}$ & $22,73.3$ & $143,80.3$ & \\
\hline Osteonecrosis of the femoral head & $2,6.7$ & $16,9.0$ & \\
\hline Others & $3,10.0$ & $4,2.2$ & \\
\hline \multicolumn{4}{|l|}{ Kellgren-Lawrence classification (n) } \\
\hline Garde II: III: IV & $0: 5: 20$ & 0: $32: 126$ & 0.977 \\
\hline Prevalent vertebral fractures $(n, \%)$ & & & 0.466 \\
\hline 0 & $22,73.3$ & $144,80.9$ & \\
\hline 1 & $6,20.0$ & $29,16.3$ & \\
\hline $2+$ & $2,6.7$ & $5,2.8$ & \\
\hline Surgeons' experience $(n, \%)$ & & & 0.310 \\
\hline$<8$ years & $2,6.7$ & $6,3.4$ & \\
\hline $8-15$ years & $16,53.3$ & $76,42.7$ & \\
\hline$>15$ years & $12,40.0$ & $96,53.9$ & \\
\hline \multirow[t]{2}{*}{ Modified Harris Hip Score ${ }^{b, c}$} & $49.2 \pm 12.8$ & $53.4 \pm 13.1$ & 0.544 \\
\hline & $66.2 \pm 7.8$ & $91.7 \pm 6.9$ & $0.038^{*}$ \\
\hline \multirow[t]{2}{*}{ Visual analogue scale-pain $(\mathrm{mm})^{c}$} & $87.6 \pm 21.8$ & $71.8 \pm 22.9$ & 0.352 \\
\hline & $22.7 \pm 13.2$ & $16.9 \pm 13.1$ & 0.611 \\
\hline \multirow[t]{2}{*}{ Visual analogue scale-satisfaction $(\mathrm{mm})^{c}$} & $84.1 \pm 14.3$ & $75.1 \pm 13.7$ & 0.747 \\
\hline & $55.9 \pm 12.3$ & $14.9 \pm 13.1$ & $0.033^{*}$ \\
\hline \multirow[t]{2}{*}{ HOOS-JR } & $48.1 \pm 13.8$ & $45.9 \pm 13.6$ & 0.917 \\
\hline & $52.8 \pm 16.1$ & $87.5 \pm 14.3$ & $0.010^{*}$ \\
\hline \multirow[t]{2}{*}{ EuroQol 5-Dimension ${ }^{c}$} & $0.43 \pm 0.17$ & $0.43 \pm 0.11$ & 0.894 \\
\hline & $0.63 \pm 0.12$ & $0.70 \pm 0.12$ & 0.125 \\
\hline \multirow[t]{2}{*}{ Trendelenburg sign $(n, \%)^{c}$} & $8,26.7$ & $43,24.2$ & 0.768 \\
\hline & $6,20.0$ & $7,3.9$ & $<0.001^{*}$ \\
\hline \multirow[t]{2}{*}{ C7 sagittal vertical axis $(\mathrm{mm})^{c}$} & $25.1 \pm 31.9$ & $22.8 \pm 33.5$ & 0.763 \\
\hline & $27.0 \pm 31.7$ & $25.2 \pm 32.9$ & 0.648 \\
\hline \multirow[t]{2}{*}{ Lumbar lordosis $\left({ }^{\circ}\right)^{c}$} & $34.1 \pm 15.5$ & $52.9 \pm 16.7$ & $0.016^{*}$ \\
\hline & $37.1 \pm 14.8$ & $50.5 \pm 17.5$ & $0.018^{*}$ \\
\hline \multirow[t]{2}{*}{ Pelvic incidence $\left({ }^{\circ}\right)^{c}$} & $45.8 \pm 13.2$ & $47.2 \pm 13.7$ & 0.691 \\
\hline & $45.6 \pm 13.5$ & $47.2 \pm 13.4$ & 0.863 \\
\hline \multirow[t]{2}{*}{ Pelvic incidence minus lumbar lordosis $\left({ }^{\circ}\right)^{c}$} & $11.7 \pm 11.7$ & $-5.7 \pm 10.7$ & $0.027^{*}$ \\
\hline & $8.5 \pm 12.1$ & $-3.3 \pm 10.1$ & 0.265 \\
\hline \multirow[t]{2}{*}{ Pelvic tilt $\left({ }^{\circ}\right)^{c}$} & $13.7 \pm 8.1$ & $13.2 \pm 10.8$ & 0.724 \\
\hline & $14.2 \pm 9.3$ & $14.8 \pm 11.3$ & 0.717 \\
\hline T1 pelvic angle $\left({ }^{\circ}\right)^{c}$ & $14.7 \pm 13.2$ & $8.5 \pm 8.1$ & $0.041^{*}$ \\
\hline
\end{tabular}


Table 1 Baseline characteristics and comparison of the disability and control groups (Continued)

\begin{tabular}{|c|c|c|c|}
\hline & $\begin{array}{l}\text { Disability group } \\
n=30\end{array}$ & $\begin{array}{l}\text { Control group } \\
n=178\end{array}$ & $P$ value \\
\hline & $15.5 \pm 13.8$ & $9.9 \pm 9.4$ & $0.032^{*}$ \\
\hline \multirow[t]{2}{*}{ T1 pelvic angle divided by pelvic incidence ${ }^{c}$} & $0.32 \pm 0.11$ & $0.18 \pm 0.09$ & $0.018^{*}$ \\
\hline & $0.34 \pm 0.14$ & $0.21 \pm 0.08$ & $0.023^{*}$ \\
\hline \multicolumn{4}{|l|}{ Complication at the reattached fragment $^{d}$} \\
\hline Total, (n, \%) & $7,23.3$ & $13,7.3$ & $0.006^{*}$ \\
\hline Type I: II: III (n) & 2: $3: 2$ & 8: 4: 1 & 0.286 \\
\hline
\end{tabular}

Data are expressed as mean \pm standard deviation or the number of hip involvement (\%) as appropriate for the data type ${ }^{*} P<.05$; represents significant between-group differences

HOOS-JR the Hip Disability and Osteoarthritis Outcome Score Joint Replacement

aPrimary hip osteoarthritis was unassociated with developmental dysplasia of the hip. The dysplasia was defined as a center edge angle of $\leq 25^{\circ}$, acetabular roof obliquity of $\geq 10^{\circ}$, or acetabular head index of $\leq 75 \%$ [20]

${ }^{\mathrm{b}}$ Composite measure covering pain and function, scored on a scale ranging from 0 to 100 , with a higher value representing improved function and decreased pain

'Between-group comparisons of outcomes pre-operatively (upper row) and at the two-year follow-up (lower row)

${ }^{\mathrm{d}}$ Tip and base fractures of the greater trochanter for Types I and II, respectively; and a migration of the osteotomized fragment for Type III [22]

height $<148 \mathrm{~cm}$ (versus a height $\geq 148 \mathrm{~cm}$; odds ratio, 1.26; $p=0.011$ ) (Table 2).

The diagnostic performance of pre-operative T1PA/PI values was assessed using the ROC curve. The cut-off value of $>0.19$ had a sensitivity of $95 \%$ and specificity of 85\% (Fig. 4). Even though there was no statistical difference between the two groups pre-operatively, except for body height $(p=0.021)$, the post-operative VAS- satisfaction $(p<0.001)$, HOOS-JR $(p=0.023)$, and EuroQol 5-Dimension 5-Level $(p=0.041)$ differed when the pre-operative T1PA/PI cut-off value was chosen as 0.2 (Table 3).

The reliability in measurement was good (intra-class correlation coefficient [ICC], 0.5-0.75) to excellent (ICC $>0.75$ ). The inter-observer agreement was higher for T1PA than for PI, SVA, and LL measurement (Table 4).

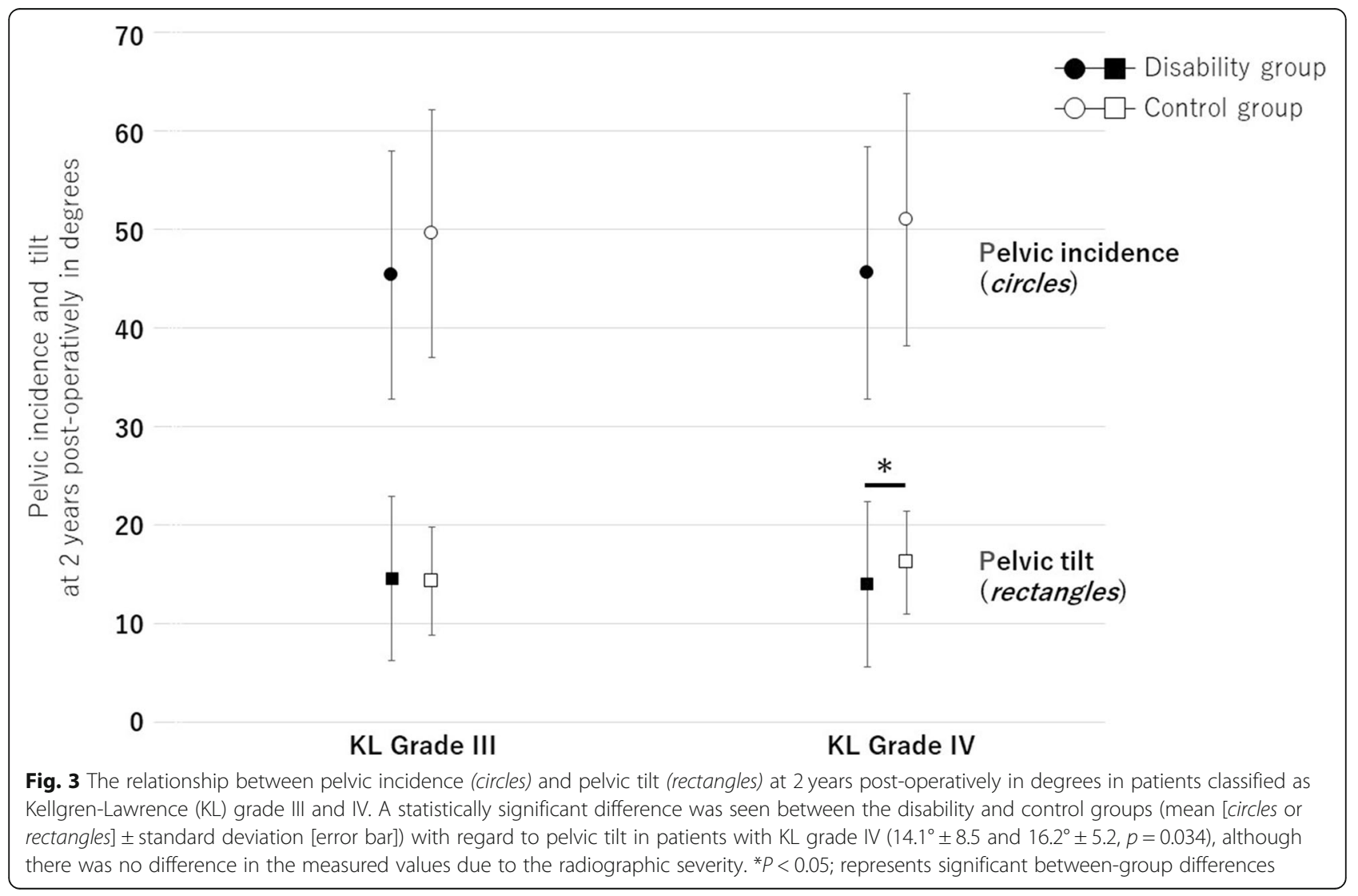


Table 2 Univariate and multivariate logistic regression analyses of the risk factors for persistent disability after total hip arthroplasty defined by the Hip Disability and Osteoarthritis Outcome Score Joint Replacement < 70/100

\begin{tabular}{|c|c|c|c|c|}
\hline & \multirow{2}{*}{$\begin{array}{l}\text { Univariate analysis } \\
P \text { value }\end{array}$} & \multicolumn{3}{|c|}{ Multivariate analysis } \\
\hline & & Odds ratio & $95 \% \mathrm{Cl}$ & $P$ value \\
\hline Age & .684 & & & \\
\hline Male & $>.999$ & & & \\
\hline \multicolumn{5}{|l|}{ Body height } \\
\hline$\geq 148 \mathrm{~cm}$ & Reference & & & \\
\hline$<148 \mathrm{~cm}$ & $.078^{*}$ & 1.26 & $1.09-1.48$ & $0.011^{* *}$ \\
\hline \multicolumn{5}{|l|}{ Body mass index } \\
\hline$\geq 25$ & Reference & & & \\
\hline$<25$ & .746 & & & \\
\hline \multicolumn{5}{|c|}{ Surgeons' experience } \\
\hline$>15$ years & Reference & & & \\
\hline 8 to 15 years & $>.999$ & & & \\
\hline$<8$ years & $.174^{*}$ & 1.18 & $0.82-1.66$ & 0.585 \\
\hline \multicolumn{5}{|l|}{ T1PA/PI } \\
\hline$\leq 0.2$ & Reference & & & \\
\hline$>0.2$ & $.012^{*}$ & 2.11 & $1.19-4.14$ & $<0.001^{* *}$ \\
\hline
\end{tabular}

The intra- and inter-rater agreements, with a discrepancy of $<2^{\circ}$, were as follows: LL, 78.2 and $84.5 \%$; PI, 81.3 and $77.5 \%$; and T1PA, 86.5 and $87.1 \%$, respectively.

\section{Discussion}

The most important finding of our study was that the preexistence of global sagittal deformity was associated with patient disability after THA at the 2-year follow-up ( $p=$ 0.010) (Table 1). Clinicians should be aware that a spinal sagittal deformity might lead to poor patient-reported outcomes after THA, particularly among patients with a T1PA/PI > 0.2 and/or a short stature (Table 2).

Previous studies that have evaluated sagittal spinopelvic parameters on THA outcomes have employed dislocation and revision as the study end-points $[4,9,11]$. Other studies have focused on evaluating measures of alignment obtained in sitting and standing postures as dynamic risk factors for dislocation $[8,10]$. Only a few studies have retrospectively evaluated the effect of the pre-operative sagittal spinopelvic alignment on outcomes after THA [23, 30, 31]. Ochi et al. found that THA patients with a pre-operatively imbalanced sagittal alignment had poorer outcomes according to the modified HHS and that pre-operative spinopelvic alignment predicted post-operative hip function at 3 to 26 months [23]. Perrone et al. proposed that patients with a high PI

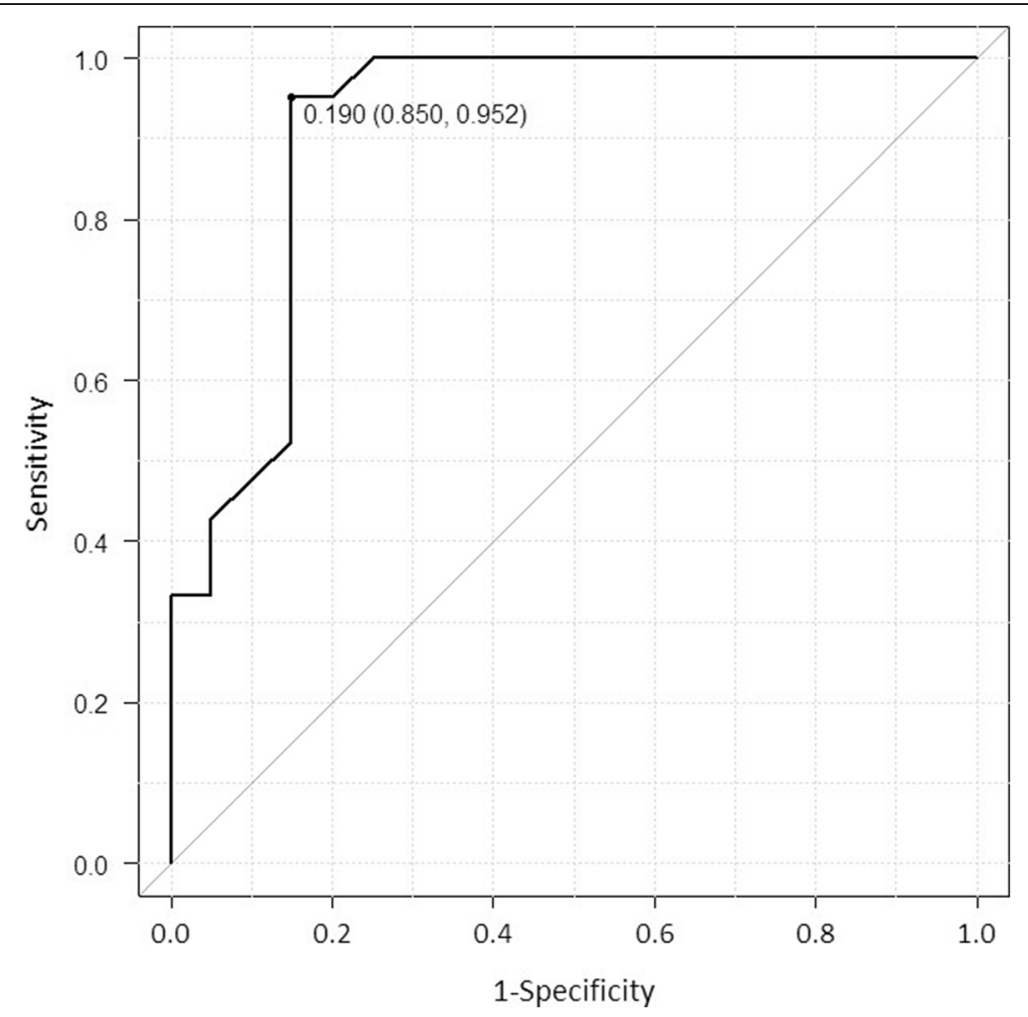

Fig. 4 A receiver-operating characteristic (ROC) curve to identify the cut-off value of the $T 1$ pelvic angle divided by pelvic incidence for predicting disability at 2 years post-operatively. The area under the ROC curve was 0.88 ( $95 \%$ confidence interval, $0.850-0.952$ ) 
Table 3 Between-group comparisons of the pre-existence of global sagittal deformity

\begin{tabular}{|c|c|c|c|}
\hline & \multicolumn{3}{|c|}{ T1 pelvic angle divided by pelvic incidence } \\
\hline & $\begin{array}{l}>0.2 \\
n=36\end{array}$ & $\begin{array}{l}\leq 0.2 \\
n=172\end{array}$ & $P$ value \\
\hline Age (years) & $74.1 \pm 6.7$ & $74.3 \pm 7.1$ & 0.653 \\
\hline Male (n, \%) & $5,13.9$ & $20,11.6$ & 0.704 \\
\hline Body height (cm) & $154.1 \pm 3.9$ & $156.6 \pm 3.3$ & $0.021^{*}$ \\
\hline Body mass index $\left(\mathrm{kg} / \mathrm{m}^{2}\right)$ & $24.2 \pm 3.6$ & $24.7 \pm 2.9$ & 0.548 \\
\hline \multirow[t]{2}{*}{ Visual analogue scale-satisfaction $(\mathrm{mm})^{\mathrm{a}, \mathrm{b}}$} & $76.1 \pm 17.7$ & $76.5 \pm 19.4$ & 0.999 \\
\hline & $27.2 \pm 20.4$ & $19.5 \pm 18.3$ & $<0.001^{*}$ \\
\hline \multirow[t]{2}{*}{ HOOS-JR ${ }^{b}$} & $46.1 \pm 12.9$ & $46.2 \pm 15.2$ & 0.773 \\
\hline & $71.2 \pm 11.7$ & $84.9 \pm 12.6$ & $0.023^{*}$ \\
\hline \multirow[t]{2}{*}{ EuroQol 5-Dimension ${ }^{\text {b }}$} & $0.42 \pm 0.13$ & $0.43 \pm 0.12$ & 0.564 \\
\hline & $0.66 \pm 0.11$ & $0.70 \pm 0.12$ & $0.041^{*}$ \\
\hline
\end{tabular}

Data are expressed as mean \pm standard deviation values or the number of hip involvements (\%) as appropriate for the data type

${ }^{*} P<.05$; represents significant between-group differences

HOOS-JR the Hip Disability and Osteoarthritis Outcome Score Joint Replacement

"Patient satisfaction after THA evaluated using a 100-mm VAS for satisfaction with anchors at "0" mm (complete satisfaction) and "100" mm

(complete dissatisfaction)

${ }^{b}$ Between-group comparisons of outcomes pre-operatively (upper row) and at the 2-year follow-up (lower row)

had a significantly better HOOS after THA than those with a low PI (56.4 versus $\left.48.7^{\circ}, p=0.006\right)$ [30]. These studies did not evaluate the relationship between global sagittal deformity and functional disability after THA.

In our study, we used T1PA/PI measures to evaluate the effects of global sagittal deformity on patient disability after THA. The T1PA combines information from both the SVA and pelvic tilt simultaneously to measure the geometry of global spinal deformity more directly [6]. Our results showed that a pre-operative T1PA/PI $>0.2$ was associated with lower satisfaction after THA $(p<0.001) \quad$ (Table 3$)$. Moreover, body height $<148 \mathrm{~cm}(p=0.011)$ was an independent risk factor for persistent disability (Table 2). A short stature, defined by a body height of $<148 \mathrm{~cm}$ equivalent to legal standards, can lead to an atypical load distribution on the spine and a delay in the process of ossification [13]. The proportion of patients with a short stature in our study group was higher than the $0.8 \%$ rate reported by Anis et al. [13] (Table 1). We did identify that patients with a T1PA/PI $>0.2$ were shorter than the others $(p=0.021$; Table 3$)$. Moreover, there was no difference between the two groups with respect to the radiographic severity of PI or PT (Fig. 3).

This study had several limitations. The main limitation was the relatively small study sample, which limited the statistical power of our results. Second, we investigated only cemented prostheses implanted using a direct lateral approach $[21,22]$. It may be difficult to apply our results to other populations. We do note that, among Asian populations, the primary indication for THA is secondary OA caused by developmental acetabular dysplasia, with a greater prevalence in women than in men $[22,23]$. In fact, only 12.0 and $8.7 \%$ of our patients were men and primary hip OA, respectively; therefore, our results cannot be generalised to other implant types, approaches, or ethnicities [4, 12, 32] (Table 1). Third, the analyses cannot be performed for dynamic changes with the patient in the sitting or supine position [7]. Lastly,

Table 4 Intra- and inter-observer reliability of the sagittal spinopelvic parameters evaluated using intra- and inter-class correlation coefficients

\begin{tabular}{|c|c|c|c|c|}
\hline & C7 sagittal vertical axis & Lumbar lordosis & Pelvic incidence & T1 pelvic angle \\
\hline \multicolumn{5}{|c|}{ Intra-class Correlation Coefficient } \\
\hline Observer 1 & $0.71(0.61-0.83)$ & $0.72(0.58-0.81)$ & $0.74(0.61-0.84)$ & $0.77(0.61-0.85)$ \\
\hline Observer 2 & $0.67(0.52-0.82)$ & $0.69(0.62-0.84)$ & $0.73(0.67-0.86)$ & $0.76(0.64-0.83)$ \\
\hline Observer 3 & $0.70(0.64-0.82)$ & $0.71(0.65-0.87)$ & $0.72(0.64-0.87)$ & $0.78(0.63-0.82)$ \\
\hline \multicolumn{5}{|c|}{ Inter-class Correlation Coefficient } \\
\hline & $0.67(0.55-0.76)$ & $0.63(0.53-0.74)$ & $0.74(0.58-0.83)$ & $0.80(0.61-0.84)$ \\
\hline
\end{tabular}

Values are given as coefficients with a corresponding $95 \%$ confidence interval in parentheses 
our follow-up period was relatively short $[14,16]$. Additional follow-up information would be required to determine long-term results [14].

Despite these limitations, our study does highlight that several pre-operative factors could affect functional disability 2 years after THA. It could be that their postoperative satisfaction merely reflects general personalities and/or medical expectations, rather than being a proxy for recovery, among other things; however, the strength of our study lies in the finding that the preoperative T1PA/PI was associated with disability after THA. Our findings are clinically relevant and indicate that spinopelvic sagittal alignment should be precisely evaluated before THA to improve patient satisfaction [11]. Sagittal alignment measurements would also help explain potential differences in PI and in compensation and may clarify the severity of OA.

The management of these individuals could include perioperative interventions, such as the prescription of an orthosis and/or physical therapy, or involve prediction of subsequent spinal surgery. In our findings, the focus on PROMs also provides novel information on possible differences among patients with and without a T1PA/PI $>0.2$; this could be helpful in setting expectations for patients and surgeons before THA (Table 4). Interestingly, the thresholds obtained from the ROC curve in this study was similar to that reported in a previous study [6] (Fig. 4). To the best of our knowledge, this is the first study about the relationship between spinopelvic alignment and PROMS after THA.

\section{Conclusion}

Global sagittal deformity, especially in patients with a T1PA/PI $>0.2$ and/or short patient stature, was associated with a higher disability rate at the 2-year follow-up after THA. Clinicians should be aware of the influence of several pre-operative factors on disability, 2 years after THA. Further studies are warranted to improve our understanding of PROMs, long-term function, and patient satisfaction after THA.

\section{Abbreviations}

Cl: Confidence interval; HHS: Harris hip score; HOOS-JR: Hip disability and osteoarthritis outcome score-joint replacement; ICC: Intra-class correlation coefficient; LL: Lumbar lordosis; OA: Osteoarthritis; OR: Odds ratio; PA: Pelvic angle; PI: Pelvic incidence; PT: Pelvic tilt; PROM: Patient-reported outcome measures; SVA: C7 sagittal vertical axis; THA: Total hip arthroplasty; VAS: Visual analogue scale

\section{Acknowledgments}

We would like to thank Editage (www.editage.com) for English language editing.

\section{Authors' contributions}

$\mathrm{YO}, \mathrm{HW}, \mathrm{TO}$ and $\mathrm{SO}$ designed the study. HW and TO obtained the data. YO wrote the initial draft. YO performed the statistical analysis. $M N$ and $Y O$ ensured the accuracy of the data and analysis. The author(s) read and approved the final manuscript.

\section{Funding}

This study was supported by the Osaka gas group Welfare Foundation and the Grants-in-Aid for Scientific Research of Japan Society for the Promotion of Science, Grant Number 21 K09239.

Availability of data and materials

The datasets used and/or analysed during the current study are available from the corresponding author on reasonable request.

\section{Declarations}

Ethics approval and consent to participate

This study was performed in line with the principles of the Declaration of Helsinki (1964) and its subsequent amendments and was approved by the institutional review board of Osaka Medical College hospital (approval number1912). Informed consent was obtained from all individual participants included in the study.

\section{Consent for publication}

Not applicable.

\section{Competing interests}

The authors declare that they have no conflicts of interest.

Received: 17 March 2021 Accepted: 26 May 2021

Published online: 07 June 2021

\section{References}

1. Anakwe RE, Jenkins PJ, Moran M. Predicting dissatisfaction after total hip arthroplasty: a study of 850 patients. J Arthroplast. 2011;26(2):209-13. https://doi.org/10.1016/j.arth.2010.03.013.

2. Berliner JL, Brodke DJ, Chan V, SooHoo NF, Bozic KJ. John Charnley award: preoperative patient-reported outcome measures predict clinically meaningful improvement in function after THA. Clin Orthop Relat Res. 2016; 474(2):321-9. https://doi.org/10.1007/s11999-015-4350-6.

3. Yeo MGH, Goh GS, Chen JY, Lo NN, Yeo SJ, Liow MHL. Are Oxford hip score and Western Ontario and McMaster universities osteoarthritis index useful predictors of clinical meaningful improvement and satisfaction after total hip arthroplasty? J Arthroplast. 2020;35(9):2458-64. https://doi.org/10.1016/ j.arth.2020.04.034.

4. Buckland AJ, Ayres EW, Shimmin AJ, Bare JV, McMahon SJ, Vigdorchik JM. Prevalence of sagittal spinal deformity among patients undergoing total hip arthroplasty. J Arthroplast. 2020;35(1):160-5. https://doi.org/10.1016/j.arth.2 019.08.020.

5. Prather H, Van Dillen LR, Kymes SM, Armbrecht MA, Stwalley D, Clohisy JC. Impact of coexistent lumbar spine disorders on clinical outcomes and physician charges associated with total hip arthroplasty. Spine J. 2012;12(5): 363-9. https://doi.org/10.1016/.jspinee.2011.11.002.

6. Durand WM, Daniels AH, Hamilton DK, Passias P, Kim HJ, Protopsaltis T, et al. The spino-pelvic ratio: a novel global sagittal parameter associated with clinical outcomes in adult spinal deformity patients. Eur Spine J. 2020;29(9): 2354-61. https://doi.org/10.1007/s00586-020-06472-x.

7. Buckland AJ, Fernandez L, Shimmin AJ, Bare JV, McMahon SJ, Vigdorchik JM. Effects of sagittal spinal alignment on postural pelvic mobility in total hip arthroplasty candidates. J Arthroplast. 2019;34(11):2663-8. https://doi.org/1 0.1016/j.arth.2019.06.036.

8. DelSole EM, Vigdorchik JM, Schwarzkopf R, Errico TJ, Buckland AJ. Total hip arthroplasty in the spinal deformity population: does degree of sagittal deformity affect rates of safe zone placement, instability, or revision? J Arthroplast. 2017;32(6):1910-7. https://doi.org/10.1016/j.arth.2016.12.039.

9. Buckland AJ, Vigdorchik J, Schwab FJ, Errico TJ, Lafage R, Ames C, et al. Acetabular anteversion changes due to spinal deformity correction: bridging the gap between hip and spine surgeons. J Bone Joint Surg Am. 2015;97(23):1913-20. https://doi.org/10.2106/JBJS.0.00276.

10. Grammatopoulos G, Gofton W, Jibri Z, Coyle M, Dobransky J, Kreviazuk C, et al. 2018 frank Stinchfield award: spinopelvic hypermobility is associated with an inferior outcome after THA: examining the effect of spinal arthrodesis. Clin Orthop Relat Res. 2019;477(2):310-21. https://doi.org/10.1 097/CORR.0000000000000367.

11. Sultan AA, Khlopas A, Piuzzi NS, Chughtai M, Sodhi N, Mont MA. The impact of spino-pelvic alignment on total hip arthroplasty outcomes: a critical 
analysis of current evidence. J Arthroplast. 2018;33(5):1606-16. https://doi. org/10.1016/.arth.2017.11.021.

12. Amlie E, Havelin LI, Furnes O, Baste V, Nordsletten L, Hovik O, et al. Worse patient-reported outcome after lateral approach than after anterior and posterolateral approach in primary hip arthroplasty. A cross-sectional questionnaire study of 1,476 patients 1-3 years after surgery. Acta Orthop. 2014;85(5):463-9. https://doi.org/10.3109/17453674.2014.934183.

13. Anis HK, McConaghy KM, Charles RJ, Warren JA, Santana DC, Klika AK, et al. Perioperative outcomes and complications after primary total hip arthroplasty in patients with disproportionately short stature: a matched cohort analysis. J Arthroplast. 2020;35(3):801-4. https://doi.org/10.1016/j.a rth.2019.10.019.

14. Galea VP, Rojanasopondist P, Ingelsrud LH, Rubash HE, Bragdon C, Huddleston lii Jl, et al. Longitudinal changes in patient-reported outcome measures following total hip arthroplasty and predictors of deterioration during follow-up: a seven-year prospective international multicentre study. Bone Joint J. 2019;101:768-78.

15. Jolbäck P, Rolfson O, Mohaddes M, Nemes S, Kärrholm J, Garellick G, et al. Does surgeon experience affect patient-reported outcomes 1 year after primary total hip arthroplasty? Acta Orthop. 2018;89(3):265-71. https://doi. org/10.1080/17453674.2018.1444300.

16. Lalani A, Lee YY, Pitta M, Westrich GH, Lyman S. Age-related decline in patient-reported outcomes 2 and 5 years following total hip arthroplasty. J Arthroplast. 2019;34(9):1999-2005. https://doi.org/10.1016/ j.arth.2019.02.023.

17. Rolfson O, Kärrholm J, Dahlberg LE, Garellick G. Patient-reported outcomes in the Swedish hip arthroplasty register: results of a nationwide prospective observational study. J Bone Joint Surg Br. 2011;93:867-75.

18. Genant HK, Wu CY, van Kuijk C, Nevitt MC. Vertebral fracture assessment using a semiquantitative technique. J Bone Miner Res. 1993;8(9):1137-48. https://doi.org/10.1002/jbmr.5650080915.

19. Legaye J, Duval-Beaupere G, Hecquet J, Marty C. Pelvic incidence: a fundamental pelvic parameter for three-dimensional regulation of spinal sagittal curves. Eur Spine J. 1998;7(2):99-103. https://doi.org/10.1007/ s005860050038.

20. Wyles CC, Heidenreich MJ, Jeng J, Larson DR, Trousdale RT, Sierra RJ. The John Charnley award: redefining the natural history of osteoarthritis in patients with hip dysplasia and impingement. Clin Orthop Relat Res. 2017; 475(2):336-50. https://doi.org/10.1007/s11999-016-4815-2.

21. Dall D. Exposure of the hip by anterior osteotomy of the greater trochanter. A modified anterolateral approach. J Bone Joint Surg Br. 1986;68:382-6.

22. Oe K, lida H, Kobayashi F, Ueda N, Nakamura T, Okamoto N, et al. Reattachment of an osteotomized greater trochanter in total hip arthroplasty using an ultra-high molecular weight polyethylene fiber cable. J Orthop Sci. 2018;23(6):992-9. https://doi.org/10.1016/j.jos.2018.07.020.

23. Ochi H, Homma Y, Baba T, Nojiri H, Matsumoto M, Kaneko K. Sagittal spinopelvic alignment predicts hip function after total hip arthroplasty. Gait Posture. 2017;52:293-300. https://doi.org/10.1016/j.gaitpost.2016.12.010.

24. Lan RH, Bell JW, Samuel LT, Kamath AF. Outcome measures in total hip arthroplasty: have our metrics changed over 15 years? Arch Orthop Trauma Surg. 2021. https://doi.org/10.1007/s00402-021-03809-z.

25. Lyman S, Lee YY, McLawhorn AS, Islam W, MacLean CH. What are the minimal and substantial improvements in the HOOS and KOOS and JR versions after total joint replacement? Clin Orthop Relat Res. 2018;476(12): 2432-41. https://doi.org/10.1097/CORR.0000000000000456.

26. Siljander MP, McQuivey KS, Fahs AM, Galasso LA, Serdahely K, Karadsheh MS. Current trends in patient-reported outcome measures in total joint arthroplasty: a study of 4 major orthopaedic journals. J Arthroplast. 2018; 33(11):3416-21. https://doi.org/10.1016/j.arth.2018.06.034.

27. Vaz G, Roussouly P, Berthonnaud E, Dimnet J. Sagittal morphology and equilibrium of pelvis and spine. Eur Spine J. 2002;11(1):80-7. https://doi. org/10.1007/s005860000224.

28. Schwab F, Lafage V, Patel A, Farcy JP. Sagittal plane considerations and the pelvis in the adult patient. Spine. 2009;34:1828-33.

29. Koo TK, Li MY. A guideline of selecting and reporting intraclass correlation coefficients for reliability research. J Chiropr Med. 2016;15(2):155-63. https:// doi.org/10.1016/j.jcm.2016.02.012.

30. Perronne L, Haehnel O, Chevret S, Wybier M, Hannouche D, Nizard R, et al. How is quality of life after total hip replacement related to the reconstructed anatomy? A study with low-dose stereoradiography. Diagn Interv Imaging. 2021;102(2):101-7. https://doi.org/10.1016/j.diii.2020.05.004.
31. Innmann MM, Reichel F, Schaper B, Merle C, Beaulé PE, Grammatopoulos G. How does spinopelvic mobility and sagittal functional cup orientation affect patient-reported outcome 1 year after THA?-a prospective diagnostic cohort study. J Arthroplast. 2021. https://doi.org/10.1016/j.arth.2021.02.014.

32. Mjaaland KE, Kivle K, Svenningsen S, Nordsletten L. Do postoperative results differ in a randomized trial between a direct anterior and a direct lateral approach in THA? Clin Orthop Relat Res. 2019;477(1):145-55. https://doi. org/10.1097/CORR.0000000000000439.

\section{Publisher's Note}

Springer Nature remains neutral with regard to jurisdictional claims in published maps and institutional affiliations.
Ready to submit your research? Choose BMC and benefit from:

- fast, convenient online submission

- thorough peer review by experienced researchers in your field

- rapid publication on acceptance

- support for research data, including large and complex data types

- gold Open Access which fosters wider collaboration and increased citations

- maximum visibility for your research: over $100 \mathrm{M}$ website views per year

At BMC, research is always in progress.

Learn more biomedcentral.com/submissions 